www.jmscr.igmpublication.org

Impact Factor (SJIF): 6.379

Index Copernicus Value: 79.54

ISSN (e)-2347-176x ISSN (p) 2455-0450

crossrefDOI: https://dx.doi.org/10.18535/jmscr/v6i10.222

\title{
Association between Protein Diet and Kidney Function Indicators in Type 2 Diabetes mellitus
}

\author{
Authors \\ Dr Pankaj Bhushan, MD (Biochemistry) ${ }^{1}$, Dr Usha Kumari DGO, MD (Biochemistry) ${ }^{2}$ \\ Dr (Prof.) U.S. Choudhary MD (Biochemistry) ${ }^{3}$ \\ ${ }^{1}$ Tutor, Department of Biochemistry, J.L.N. M.C.\& H, Bhagalpur. \\ ${ }^{2}$ Assistant Professor, Department of Biochemistry, J.L.N. M.C.\& H, Bhagalpur \\ ${ }^{3}$ Prof. \& HOD, Department of Biochemistry, J.L.N. M.C.\& H, Bhagalpur, India
}

\section{Introduction \& Review of literature}

Role of diet is very important in normal person as well as patients with diabetes mellitus particularly type 2 DM. Vegetarian protein diet have no damaging effect on kidney functions indicators while non-vegetarian diet directly or indirectly related to the damaging effect on the kidney function indicators of type-2 DM. This association is significant in many studies.

Diabetes Mellitus is a group of disease causing metabolic hyperglycemia leads to macro vascular and micro vascular complications causing significant morbidity and mortality among diabetic people. Etiologically, Type 1 Diabetes Mellitus is characterized by P-cell destruction caused by an autoimmune process, leading to absolute insulin deficiency where as Type-2 Diabetes Mellitus is characterized by insulin resistance in peripheral tissues and an insulin secretory defect of the B-cell. According to WHO-globally, the number of people with diabetes is expected to rise up to 300 million (prevalence rate $5.4 \%$ ) by the year 2025 . There are 66.8 million people with diabetes in India in 2015 and this number is predicted to rise up to 70 million by 2025 . By that time every fifth diabetic person will be an Indian. Therefore, Joshi SR et al (2007) stated India- "Diabetic Capital of the world." According to Joshi SR et al (Diabetes care in India) diabetes mellitus has emerged as a major health problem in India. India currently represents 49 percent of the world's diabetes burden, with an estimated 72 million cases in 2017. Diabetes prevalence has increased by 64 percent across India over the quarter-century, according to a November 2017 report by the Indian Council for Medical Research, Institute for Health Metrics and Evaluation, both research institutes, and the Public Health Foundation of India, an advocacy. Diabetic Nephropathy, retinopathy and neuropathy are most common complications of uncontrolled diabetes mellitus. The risk of chronic complication in diabetic patients depends on duration of hyperglycemia and usually manifested after 10 years. Diabetic Nephropathy is one of the common causes of morbidity and mortality in diabetic patients. Pathogenesis of Diabetic glomerulopathy is due to (a) formation of advanced glycation end products (b) Activation of protein kinase-c and (c) Intra cellular 
hyperglycemia with disturbance in polyol pathway. Advanced glycation end products (AGEs) are formed as a result of non-enzymatic reactions between intracellular glucose derived dicarbonyl precursors with amino group of both intracellular and extracellular protein and promote glomerular dysfunction. In the capillaries of renal glomeruli albumin binds to the glycated basement membrane causing increased basement membrane thickening which is characteristic of diabetic microangiopathy. The capillaries of glomeruli with the thickened basement membrane are more leaking than normal capillaries to the plasma proteins. The microangiopathy is the basic pathogenesis for development of diabetic nephropathy. "Proteinuria" refers to increase in urinary excretion of albumin and other specific protein or total protein where as "Albuminuria" refers to increase in urinary excretion of albumin specifically. "Microalbuminuria" refers to albumin excretion above the normal range 30 to $300 \mathrm{mg} / \mathrm{d}$ but below the level of detection by test for total protein. It is a known fact that the smoking increases the risk of diabetic nephropathy and causes Microalbuminuria. Albumen creatinine ratio increases in Type 1 Diabetes mellitus and Type 2 Diabetes both. However, Koya D et al (2009 oct) studied 112 type 2 diabetes patient in Japan of which all 112 diabetic patients progress to overt nephropathy. They concluded that in low protein group overall protein intake was slightly but no significantly lower, it did confer association with diet.

Choi YE et al (2008mar.) observed that soya beans have been shown to be reduce urinary albumin excretion and total cholesterol in nondiabetic patients with nephrotic syndrome and concluded that soya beans may prevent the weight loss and morphological disruption of the kidney associated with diabetes mellitus. Soya beans also may improve glycaemic control and could prevent progression of diabetes mellitus and therefore, nephropathy could be prevented. Viswanathan $\mathrm{V}$ et al (2002) studied 405 type 2 diabetic patients, of which 155 patients were vegetarians and 250 patients were non-vegetarians. They found that mean Albuminuria (mg albumin/mg creatinine) was $67.5+\_38.6$ in vegetarian patients and $72,5+$ 45.9 in non-vegetarian patients. They concluded that the prevalence of Microalbuminuria was not significantly different between the two groups. But show the association between non-vegetarian \& type 2 DM

\section{Aims and Objectives}

Diabetes mellitus is the major health problem in India. It is established fact that protein diet restriction has a beneficial effect in slowing the progression of diabetic renal disease in human being .Many discoverer observed that the risk of developing DM is slightly increased in case of Non vegetarian. In our view it is essential to prevent the progression of renal damages and other complication of type 2 diabetic patient by decreasing protein diet and to keep their blood sugar within normal limit. Therefor, we designed a study on association between Protein Diet and Kidney Function Indicators in Type 2 Diabetes mellitus

\section{Materials and Methods}

The present study has been conducted with the main objective of estimating albumin creatinine ratio (urinary albumin: urinary creatinine) \& Urinary creatinine in patients of diabetes mellitus of type-2 in vegetarian and non- vegetarians groups. The place of the study was Department of Biochemistry, J. L. N Medical College, Bhagalpur, Bihar, India during 2016 to 2017.

Material: - Total 50cases having diabetes mellitus were suffering from the disease for 10 years or more and 50 cases of normal healthy individuals were selected from medical outdoor and indoor Department of Medicine JLNMC Bhagalpur.

\section{Inclusion criteria}

50 cases of known type 2 diabetes mellitus selected and divided into two category-vegetarian numbered 25 cases and non-vegetarian numbered 25 cases 
These cases were compared with the normal person having non-diabetes and non-smokers. There were 50 normal healthy individuals of both sexes range of age group from 20-50 years were selected for control.

\section{Exclusion criteria}

A. Cases having Proteinuria detectable by dipstick tests.

B. Cases having any evidence of infection established by of estimation:

1. Spot urinary albumin

2. Spot urinary creatinine

3. Fasting plasma glucose

4. $\mathrm{R} / \mathrm{E}$ of urine

5. Urine $\mathrm{C} / \mathrm{S}$ test etc.

\section{Methodology}

\section{Collection of urine sample}

Urine sample were collected in clean, sterile plastic container. Collected urine sample were tested by dipsticks for the presence of frank Proteinuria

Dipstick negative urine sample were used for quantization of albumin and creatinine within 4 hours of voiding.

\section{Collection of Blood sample}

Blood samples were collected after 12 hours of fasting. Approximately $1 \mathrm{ml}$ of venous blood drawn. It was transferred to sodium fluoride vial and then mixed gently then it was centrifuged at $3000 \mathrm{rpm}$ for 5 minutes. Plasma was pipetted out and kept in a clean steriale vial.

\section{Method of urinary Albumin Estimation}

Urinary albumin was estimated by immunoturbidimetric method (Bio Systems' Costa Brava, 30 Bance- kiba (Spain)

\section{Method of urinary creatinine Estimation}

Urinary creatinine is estimated by Modified Jaffe Method.

Fasting Plasma Glucose were estimated by GOD-POD Method.

\section{Observation}

Table-1

\begin{tabular}{|l|c|c|}
\hline Group & Type of cases & No. of cases \\
\hline I & Control & 50 \\
\hline II & Type 2 diabetes mellitus & 50 \\
\hline Total: & & 100 \\
\hline
\end{tabular}

Showing the distribution of cases.

Table -2 Showing the number of cases, means, standard deviation and standard error of mean value, $t-$ value, $p$-values and coefficient of determination of Albumin creatinine ratio with cases of vegetarian and non-vegetarian diabetics.

\begin{tabular}{|c|c|c|c|c|c|c|c|c|c|}
\hline $\begin{array}{c}\text { No. of } \\
\text { cases }\end{array}$ & Habit of Diet & $\begin{array}{c}\text { No.of } \\
\text { cases }\end{array}$ & $\begin{array}{c}\text { Mean of } \\
\text { ACR }\end{array}$ & SD & SEM & $\begin{array}{c}\text { 't' } \\
\text { Value }\end{array}$ & $\begin{array}{c}\text { 'p' } \\
\text { Value }\end{array}$ & $\mathrm{r}^{2}$ & Remark \\
\hline \multirow{2}{*}{$\begin{array}{c}\text { Type } 2 \\
\text { diabetes } \\
\text { mellitus }\end{array}$} & Vegetarians & 25 & 48.11 & 32.69 & 6.18 & \multirow{2}{*}{ Non- } \\
\cline { 2 - 10 } & 25 & 50.93 & 31.40 & 6.04 & 0.06 & 0.95 & 0.01 & Significant \\
\hline
\end{tabular}

$\mathrm{r}^{2}=$ coefficient of determination

Table- 2 shows mean albumin- creatinine ratio values in non-vegetarian increases than vegetarian group and t-score of vegetarian to non-vegetarian and correlated significant $\mathrm{p}$-trend is 0.95 . That means ACR is increases.

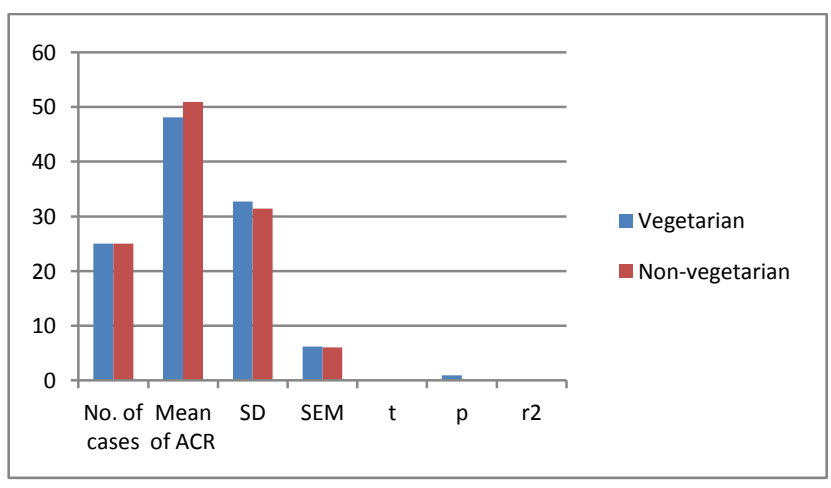


Table-3 Showing the number of cases, means, standard deviation and standard error of mean value, $\mathrm{t}$ - value and p-values, coefficient of determination ( $\mathrm{r} 2$ ) of urinary creatinine with cases of vegetarian and nonvegetarian diabetics.

\begin{tabular}{|c|c|c|c|c|c|c|c|c|c|}
\hline Group & Habit of Diet & $\begin{array}{l}\text { No. of } \\
\text { cases }\end{array}$ & $\begin{array}{c}\text { Mean of } \\
\text { Urinary } \\
\text { creatinine }\end{array}$ & SD & SEM & $\begin{array}{c}\text { ' } \mathrm{t} \text { ' } \\
\text { Value }\end{array}$ & $\begin{array}{c}\text { 'p' } \\
\text { Value }\end{array}$ & $\mathrm{r}^{2}$ & Remark \\
\hline \multirow{2}{*}{$\begin{array}{l}\text { Type-2 } \\
\text { diabetes } \\
\text { mellitus }\end{array}$} & Vegetarians & 25 & 49.41 & 7.94 & 1.58 & \multirow{2}{*}{-1.67} & \multirow{2}{*}{0.01} & \multirow{2}{*}{0.01} & \multirow{2}{*}{ Significant } \\
\hline & $\begin{array}{c}\text { Non- } \\
\text { Vegetarians }\end{array}$ & 25 & 53.20 & 8.14 & 1.62 & & & & \\
\hline
\end{tabular}

$\mathrm{r}^{2}=$ coefficient of determination

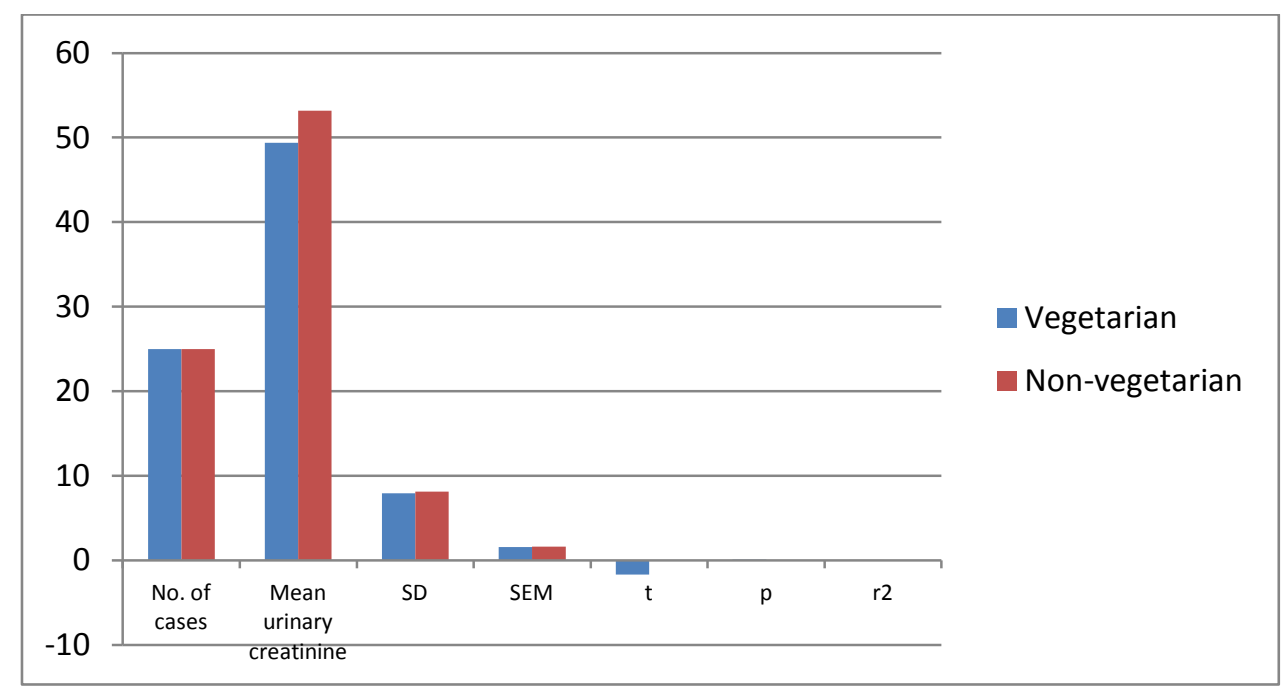

Table- 3 shows mean urinary creatinine values in non-vegetarian increases than vegetarian group and correlated significant $\mathrm{p}$-trend is $0.101 . \mathrm{r}^{2}$ is 0.01 show that mean urinary creatinine is increases non-vegetarian.

\section{Discussion and Result}

In (Table-2) 25 cases of type 2 diabetes mellitus who were vegetarians, the mean albumin creatinine ratio was found to be 48.11 while in 25 cases of type 2 diabetes mellitus who were nonvegetarians, the mean albumin creatinine ratio was found to be 50.93 .

When the difference of mean albumin creatinine ratio was compared between vegetarians and nonvegetarians type- 2 diabetic patients, it was found to be statistically significant association $\left(\mathrm{r}^{2}=0.01\right)$. In (Table-3) 25 cases of type 2 diabetes mellitus who were vegetarians, mean urinary creatinine was found to be 49.41 while in 25 cases of type 2 diabetes mellitus who were non-vegetarians, the mean urinary creatinine was found to be 53.20 .When the difference of mean urinary creatinine was compared between vegetarians and nonvegetarians type- 2 diabetic patients, it was found to be statistically significant association $\left(\mathrm{r}^{2}=0.01\right)$. Koya D et al (2009 oct) studied 112 type 2 diabetes patient in japan of which all 112 diabetic patients progress to overt nephropathy. They concluded that in low protein group overall protein intake was slightly but no significantly lower, it did confer association with diet.

Choi YE et al (2008mar.) observed that soya beans have been shown to be reduce urinary albumin excretion and total cholesterol in nondiabetic patients with nephritic syndrome and concluded that soya beans may prevent the weight loss and morphological disruption of the kidney associated with diabetes mellitus. Soya beans also may improve glycaemic control and could prevent 
progression of diabetes mellitus and therefore, nephropathy could be prevented.

Viswanathan V et al (2002) studied the prevalence of Microalbuminuria in vegetarian and non-vegetarian of type 2 diabetes mellitus and found that the prevalence of Microalbuminuria was not significant between the two groups .But show the association between non-vegetarian \& type2 DM.

Nath Ka et al.,(1986), Maschio G et al.,(1982), Ihle BU et al.,(1989), Rosman JB et al.,(1984), and El Nahas AM et al.,(1984) have suggested that dietery protein restriction has a beneficial effect in showing the progression of diabetic renal disease in human being.

\section{Conclusion}

We concluded that the person taking Healthy vegetarian protein diet may have better kidney function in type 2 diabetes. When regression analysis applied low significant regression coefficient found. This indicate that further prospective studies with large sample sizes and use of sensitive indicators for studying early renal function decline are needed to confirm this association.

However it should be emphasized that the diabetic patients particularly type- 2 should change their life style and put them on good quality vegetarian protein diets like milk, Mushroom, Soya protein, Beans, Nut and Almonds etc. Again it is better to laugh and live with nature and natural resources and to make a harmony with environment and individuals. Live and Let them live, say no to nonvegetarian food for a type 2 Diabetic patient and release your endorphins to control your happiness.

\section{Bibliography}

1. Indian Council for Medical Research, November 2017

2. Joshsi SR (diabetes care in India ) 2015

3. Koya D et al Diabetologia; 52(10):203745:Epub.2009 Aug,4

4. Choi YE et al. :Evid Based complement Alternate Med.2008 March ,20
5. Joshi SR.J. Assoc Physicians India; 55:323-24,2007

6. Viswanathan V. Indian J Nephrol;1 2:7376,2002

7. Nath Ka et al.J Clin Invest;78:1199-1205, 1986. 